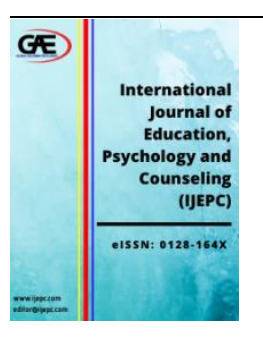

\author{
International Journal of Education, \\ Psychology and Counselling (IJEPC) \\ Journal Website: http://ijepc.com/ \\ eISSN: 0128-164X
}

\title{
COMPUTER ORIENTED LANGUAGE LEARNING APPROACH (COLLAP) FOR STRUGGLING READERS
}

\author{
Jayson A. Quinto ${ }^{1 *}$, Editha V. Rana ${ }^{2}$, Juana Nimfa P. Abrigo ${ }^{3}$ \\ 1 Demesa Elementary School, Department of Education, Philippines \\ Email: jayson.quinto001@ deped.gov.ph \\ 2 Alaminos District, Division of Laguna, Department of Education, Philippines \\ Email: editha.rana001@deped.gov.ph \\ 3 San Miguel Elementary School, Department of Education, Philippines \\ Email: juananimfa.abrigo@deped.gov.ph \\ Corresponding Author
}

\section{Article Info:}

Article history:

Received date:02.02.2020

Revised date: 21.04 .2020

Accepted date: 14.06 .2020

Published date: 15.06 .2020

\section{To cite this document:}

Quinto, J. A., Rana, E. V., \& Abrigo, J. N. P. (2020). Computer Oriented Language Learning Approach (COLLAP) for Struggling Readers. International Journal of Education, Psychology and Counseling, 5 (35), 249-269.

DOI: $10.35631 / \mathrm{IJEPC} .5350022$.

\begin{abstract}
:
This action research applies the concept of hybrid instruction, as an instrument in developing reading comprehension skills of 35 grade 6 struggling readers of Demesa Elementary School. The study adopts the descriptive quantitative, that gauges the positive effects of technology-based instruction using online learning modules, through the use of computers and or other available digital technology and platforms capable of performing prescribed learning activities. The identified struggling readers engage in 20 stories in whichever they prefer; distant learning or face-to-face instruction. They engage with the online modules through viewing, listening, reading, and comprehension check. To interpret comprehension level, the software generated scores of each pupil in every story are converted to a percentage. Once they had finished the online modules they have undergone a postassessment test. The result of both pre and post assessment, comparison of data through T-Test Two-Sample Assuming Equal Variance reflects a 66\% increase in reading comprehension. This technological approach in ameliorating comprehension skills through established techniques facilitate learners in processing ideas to be able to answer comprehensively. This also shows that digital technology is more motivating among learners especially that their age is inclined in digital media. Pupils are eager and easily learn in times they are interested in things they are doing; intrinsic motivation became part of the comprehension process. The increase in reading comprehension of target participants tells that COLLAP is a powerful tool in distance learning that it can be catered in times when face-to-face instruction is not applicable due to the absence of learners. This also shows that parents have an integral part in enriching their learners' academic performance, their participation, as well as their support, becomes the key factor of children's achievement in both distant learning and face-to-face instruction.
\end{abstract}




\section{Introduction}

"The student of the future will demand the learning support that is appropriate for their situation or context", (Specht, 2015). Delivery of instruction matters in dealing with the learning needs. The selection or use of learning materials should consider appropriateness to generation to be able to teach them well and make them learn. Thus, the educational system is a never-ending process of improvement to meet the requirements of the changing environment.

In response, this action research centers on the use of digital technology and platform as a modality of instruction for the improvement of reading comprehension or the ability to process information and able to understand meaning and recall information (Rutzler, 2017). Adapting the practice of hybrid instruction, wherein learning interaction and delivery of instruction among teachers, parents, and pupils happen on two possibilities, online or face-toface engagement. The constant mentoring and motivation develop comfort and provide support among learners as they engage in an online or computer operated task. This is the means designed for struggling readers after further investigation of their academic performance. Wherein investigation result characterized them as learners equipped with word recognition ability and in a furnishing stage for fluency and accuracy but lacking the proficiency to apply essential comprehension skills.

Through the legal support of Department of Education (DepEd) Order No. 78, Series 2010, known as, "Department of Education Computerization Program and Integration of ICT", in line with the modernization of teachers instruction gives authority and encouragement to use technology as instructional materials in delivering quality education. Thus, DepEd duly recognizes the effectiveness of computer-aided and other technological platforms as a medium of instruction in ensuring the quality of learners as products of the technological institution to satisfy the demands of the digital community.

In the study conducted by Ghazizadeh and Fatemipour, (2017) to the Iranian EFL Reading Proficiency, they found a positive effect in the use of hybrid instruction to their participants. Similar to the process in this study and supporting the effect of computer-oriented language learning to the reading proficiency specifically to the comprehension of struggling readers. The study they conducted to the EFL and this present study to ESL have almost the same implication.

The implementation of computer-assisted instruction as an endeavor of Philippine Education is one of the contributing factors to the attainment of educational objectives. According to the report of the United Nation (UN), in the aspect of literacy in the Southeast Asia the Philippines rated 97.95\%, (Philstar, 2019). This is evidence of the improvement of Philippine Literacy for the past seven years since its continuous amelioration. The staggering number of children in the country facing challenges reflected by the gap relative to the Philippine population shows that still, the country is urging for quality education for all, a functional one. This needs immediate attention, especially that the National Economic and Development Authority (NEDA) aims that all youth of the same age men and women achieve literacy by 2030, (Edillan, 2018). 
A child who is able to develop reading skills at an early age is expected to be successful in their academic performance in school (Leahy and Fitzpatrick, 2017). It is a fact that this study is conducted among grade 6 learners, to upgrade their comprehension skills and able to academically perform the competencies expected of them in the next stage. COLLAP ensures that no learners are left behind to struggle in the succeeding year due to failure in mastering the skills required in their academic level. The key ability to comprehend is necessary for it is the gateway to understand all other learning areas. Consequently, struggling readers' failure to comprehend foresees a failure to develop mastery of other learning competencies.

This research also recognizes the role of parents as the primary ingredient of success. Stated in the blog in k12 Learning Liftoff, (2017) it is not the economic status that determines the academic performance of children, relatively it is the parents' participation in their scholastic development. Thus, parents' involvement boosts struggling readers' self-esteem and refines them in more appropriate behavior. Parental guidance is also important especially that it is a digital application and has a wider world to explore. Pupils should be carefully led to the right track and secure them of any potential harm computers might bring to their minds.

COLLAP as one of the hybrid instructional approaches caters to another means to develop comprehension skills that can be considered by educators or teachers as a treatment in handling the reading issue of the same scenario. For the concerns of individual differences as a factor of teaching and learning, COLLAP might be effective for the 35 struggling readers but might not for others with the same learning difficulty (LD). However, this also can be used as a basis in developing another approach in remediating reading disability, because society changes so as well the educational system must continuously develop to meet the needs of the learners.

This action research gives clear evidence on the development of the reading comprehension of the struggling readers as the implementation of the program goes on. The effect of COLLAP through the comparison of pre and post results and the significant difference it made to the struggling readers. Furthermore, it gives us a clear procedure of how it is done and the contributing elements affecting the result to the struggling readers.

\section{Literature Review}

Much of the related literature discussed in this section focus on the importance of enriching reading comprehension skills and the vital role of digital technology and platform in transferring knowledge to the struggling readers supported by different learning theories.

\section{Overview}

Reading is not just about word recognition alone, but it is incorporated with comprehension. A child at an early age must be exposed to phonology to acquire the ability of spoken language, word sound recognition, to pronounce words accurately and properly. As the process goes on, they then learn semantics or meanings whether formal, lexical, or conceptual through the application of schema or background knowledge together with new information and so process critical thinking- the characteristic of an essential comprehension. It enables them to understand literature that leads to knowing the author, his purpose, and background and applying it in the present context.

According to Amin, (2019) that understanding reading comprehension approaches results in an improvement in reading skills. Comparatively clear, that readers with lots of experience in 
reading able to choose comprehension strategies suitable to the characteristics of the story, and that is the reason he/she can comprehend, on the other hand, pupils who have less reading experienced encounter difficulty in choosing which strategies he/she will use to comprehend the text, (Suyitno, 2017). Thus, teaching reading should be in sequence according to the level of difficulty and must be taught through different strategies especially to beginning readers and with those reading difficulties.

The rise of the digital age as a medium for delivering instruction has positive feedback. The application of hybrid and computer-assisted instruction as mentioned by John Dewey, cited by Tobler, (2015) is the adoption of education to the evolving community. Proven in many technological education researchers are the remarkable result in the use of the technological platform in delivering instruction and improving reading comprehension skills. Similar to other instructional materials, the use of technological platforms have limitations which are also the safeguard to prevent struggling readers from misleading information for it caters to a wide range of information, and to prevent negative effects of computer-aided instruction on health and academic performance of selected participants.

Struggling Readers can also be characterized as mindless readers or reading without the understanding of the printed text hence, they must be taught of several approaches of efficacious readers to be able to comprehend, (McEwan, 2020) because reading comprehension greatly relies on some cognitive and linguistic procedure, (Maloes et al, 2017). This study considered the schema or learning experience of the populations to be able to give them what they need, Thus it focuses on a simple to complex or developmentally sequenced comprehension to ensure that participants do not remain on the same level of questioning but to an increasing level of difficulty, in behalf of the remarkable support of parents and teachers which touches the behavioral side of the participants. Supported the argument of Hung, (2001) on how learning is acquired and developed.

\section{Reading Comprehension}

According to Estremera and Estremera, (2018), reading is a complex process that includes sensation, comprehension, application, and perception. This statement concerning this study implies that reading is not only about diction, precise pronunciations, or just mastering phonemes. Exhibiting such talent is mastering word recognition alone is not enough to justify individual reading skills hence, reading is a broader understanding; ideally, it is the involvement of the four features mentioned which are all considerable factors in the selection of stories used during implementation of COLLAP.

Reading is essential and no beginning readers must be left behind. Different researches prove that good readers succeed academically in the future. According to Kucukoglu, (2012) developing and learning the skill of reading strategy is the first and essential skill that a good reader must possess. Similar to the problem met in this study is the lack of capacity of the struggling readers to comprehend due to the absence of strategies. A beginning reader to be able to read must first learn the basic skill of reading and as he continues, he furtherly discovers new comprehension techniques independently. Thus, beginning readers must be taught of comprehension strategies from simple to complex so as they continuously engage they independently learn other skills relevant to their needs. In addition to Kucukoglu's enumerated strategy, comprehension must be developmentally sequenced to meet the target learning. It is the assurance of this research focus on the ladderized level of comprehension approaches. 
1.1. Literal- this is the basic comprehension level that requires reading between the lines. Understanding and getting information about what was directly written or stated in the text names, dates, time, etc. Some techniques are skimming, scanning, finding key information, and summarizing, (Department of Education, 2019).

1.2. Interpretation- this comprehension component is reading beyond the text and finding meaning from what one has already known and applied it in the context. It is understanding the scenario, situation, and instances in the story. Some skills used in inferring are identifying the main idea, understanding the author's purpose, determining point of view and predicting, (Essential Reading Comprehension Skills, 2015).

1.3. Critical-this elicit, analysis, judgment, synthesis in the author's point of view as well as the readers' point of view. According to Huggins, (2009), critical comprehension requires judgment about what they are reading and determining whether it is factual, or opinion based on evaluation of the text.

1.4. Applied- draw from the child his way of visualizing things based on his scheme. It is the combination of the author's perception and the reader's background experiences. Some of the strategies are; making a generalization, comparison, judgments, recommendation, suggestions, decision and creating an alternative ending, (Three Level Comprehension Guide for Active Reading, n.d.).

Comprehension can also be developed through the use of technology. Supported by Abba, Mustapha, and Ali, (2019), computer-aided instruction improves the language learning ability of pupils, their vocabulary, and understanding thus language learning does not only improve academic performance in language but as well as other learning areas. In this study, it is recognized as the primary gateway for science, mathematics, English, Filipino, and other learning areas to be functional. It is not limited to reading stories rather it includes listening and viewing. According to Longsdon, (2019) the scenario of reading words and recognition without remembering or understanding the text is a learning disability (LD). The scenario that needs to immediately be prevented. Comprehension is more of knowing and understanding the meaning of words considering the situation or the events in the story and decoding meaning. To comprehend is crucial functional literacy for it leads to selfdevelopment and development of the whole, so they were able to communicate and understand one another, (UNESCO Institute for Statistics, n.d.).

\section{Computer-aided instruction and Language Learning}

A great American Education Reformist John Dewey once said, "If we teach today as we taught yesterday, we rob our children of tomorrow", (Tobler, 2015). This quote explains that education is perpetual evolution and the manner of delivering instruction should also unrelentingly meet the changing demands of the community. We have to continuously transform our ways and techniques to suit our clientele in such a way that they will not be left behind by the dynamic global education.

Since the early 1900 technology has become an integral part of instruction. It becomes the common aide of teachers in facilitating and delivering learning. It is the tools in the classroom that provide options in language learning, (Ahmadi, 2018) computer facilitates delivering learning and it continuously evolved with a new development: educational software and gadgets to cater to a wide range of information. 
Based on a meta-analysis by Pearson as cited in the Essay Coupons, (n.d.) most of the published studies reveal that using technology in reading comprehension among middlegrade participants is effective. Through the use of digital technology and hands-on manipulation of computers, they are learning two skills, basic computer operation and comprehension. Animated videos and technology operated tasks are both motivating to pupils, as a result; it triggers their eager participation in learning. The use of video animation through the available digital platform, as a means to deliver the story and to answer online modules, keeps the pupils' momentum in activities they are engaged with. Consequently, intrinsic motivation became part of their will to learn, a good indicator of preparedness and inclination for self-learning.

Using digital media creates wider opportunities to overcome reading difficulties, (Scaraldi, 2017) As cited, similar to this study, struggling readers had interactive reading experience and navigated the way they can comprehend compared to a printed text. This study is found beneficial, they are much willing to use digital media than the printed text they are audiovisual learners which is consistent with the same research on the Effectiveness of audiovisual aids in Teaching, (Tang Kuok Ho \& Intai, 2018).

Technology-assisted instruction particularly video technology is more inviting and eyecatching instructional materials in the school (Abragan \&Hambre, 2017). It is observable that when children watch movies of their interest, they are starting to focus their attention, settle down, and firmly glued their eye on the screen. Their study supports that struggling readers are motivated to learn since they were hindered with their difficulties in understanding the printed text, stories must be presented through animated video to trigger and catch their attention. A child may not be able to read and understand the printed text but through the visual presentation, they might be able to appreciate and understand.

According to Ponce, Richard, and Lopez, (2013) watching videos before reading might affect comprehension skills. It gives the visual interpretation of what is in the printed text. It helps them formulate ideas related to it; sequence of events, transitions, portrayals, and utterances, because animation video is a package of three macros skills: listening, reading, and viewing, a visual interpretation of utterances, gestures, and emotions. Thus, audiovisual presentations support the formulation of meaning to understand and easily process comprehension. Struggling Readers are much attentive in listening, watching, and reading through captions. This proves that pupils who exhibit a lack of interest in learning are those classified struggling readers. Based on the Assessment through data gathering struggling readers mostly exhibit behavioral problems. They neglect to read and participate in learning activities because they fail to understand what they have read. Most of them find gadgets and digital media more motivating than printed text. This scenario was also mentioned in the Eliminating Illiteracy, Modernizing Education \& Strengthening Tolerance, (n.d.) in which, one of the enumerated problems is the curriculum; pupils tend to misbehave because they find boredom in the curriculum not suitable for their scholastic capability.

\section{Computer Oriented Language Learning Theories}

Mentioned by Spencer, (2015) in her blog that a child with little background knowledge leads to poor comprehension and leaves the reader feeling helpless. This shows the importance of schema in the organization and reorganization of thoughts adopting old information to the new one in processing comprehension. Supported by Wang, (2014) that readers' comprehension ability roots in prior knowledge, for some reason that meaning is assembled aspect repetition of the interactive process of new and old knowledge. This action research Copyright (C) GLOBAL ACADEMIC EXCELLENCE (M) SDN BHD - All rights reserved 
applies the constructivist concept of reading comprehension as an active and fabricated process of creating meaning through interaction between readers and animated video with captions or subtitles, wherein formulation of meaning greatly relies on pupils reading characteristics in meaning-making, (Yusfarina et al., 2012). Considering the investigation findings, selected stories used as materials for struggling readers touch their experiences, culture, and background knowledge. Adopting the findings of the study conducted by Altin and Saracaloglu, (2018) that reading materials based on the culture of the reader enrich vocabulary and perspective towards English Lesson. Their study shows that vocabulary as an ingredient for effective comprehension in the printed text helps learners understand the story especially that language use is L1. The findings in their study became bases in the selection of stories used in this present study.

The theory of behaviorism is also applied in this study through teachers and parents responsibility of an organized time table of activities in a bottom-up, a type of information processing which emerges from simple to complex system, (Wikipedia, n.d), reading comprehension instruction and by proving struggling readers developmental sequential online module activities which are from word recognition to comprehension, (Robinson, 2018). Conforming to Bonnamy, (n.d.) that learning happens when information is broken into little parts, to help readers easily digest the meanings.

The relentless effort of parents as teacher partners in ensuring that learning takes place is unprecedented. Their role in developing learning habits among struggling readers is good for a learning start-up. As defined by Gans, (2019) "Behaviourism is a theory of learning based on the idea that all behaviors are acquired through conditioning." Mentioned in this study the repetition of ladderized level comprehension in all stories enhances understanding skills because this leads to mastering the comprehension strategies. On the other hand, this repetition does not lead to rote memorization since strategies on dealing with comprehension level should be mastered but the question itself is not repeated, for it must direct them in different avenues of strategies.

From a cognitivist point of view with this action research, as prescribed by the arguments presented in the study of Hung, (2001) that knowledge is constructed based on the transmission of direct instruction and pupils construct knowledge on their own. As presented by Keyser, (n.d.) that if a child is not ready to his grade must be taught back to the solid foundation of cognitive skills. Taking into consideration the skills and mental process of the struggling readers proves that they are left behind in reading ability appropriate to their age, only three of his given skills were included; attention, memory processing, and visual perception. Struggling readers should be guided properly to acquire expected development, that transmission of skills in applying strategies and cognition activities included in the systematic process, simple to the complex will definitely and able to increase their reading comprehension ability (Yusfarina et al., 2012). Hence, teachers and parents should impart the ability to comprehend among struggling readers suitable to their mind processing ability and must be systematic to help them construct meaning from their own with a combination of what they know. Through this way, they continuously acquire knowledge as a combination of what was transmitted, what they have learned, and how they should respond in a new scenario. As suggested by McEwan, (2020) cognitive strategies should be directly taught and modeled among struggling readers to improve their retention and comprehension skills since cognitive strategies are extraction and construction of meaning from the text and oneself. 


\section{Research Methodology}

In this part the research methodology used in the study is discussed; the study design, selection of the participants, and the environment where the action research was conducted. The materials used in the conduct of this study and the collection of data procedures including methods implemented to maintain the validity and reliability of the instruments are also described.

\section{Research Design}

Execution of good research practice required a researcher to gain a thorough understanding of a variety of available research methodologies. Moreover, it is an undeniable fact that one needs this to carefully select the most suited methodology to apply to a particular study to be undertaken.

Specifically, the researcher uses the experimental quantitative approach as defined by USC Libraries, (2020) it determines the relationship of independent variables to dependent variables, wherein population were measured before and after an intervention.

As characterized by the research approach, before the actual conduct of COLLAP all aspects of the study were carefully designed. So, the researchers conduct thorough investigations and interviews related to struggling readers' family and economic background as well with their academic performance and rely on anecdotal records to learn more about them. An interview with the parents and struggling readers was also conducted to further support the prevailing written information gathered. They also underwent a medical test, particularly, hearing and vision screening because they are going to engage in a remediation program that auditory, visual, and tactile.

To arrive at the assumption, determining the compatibility of COLLAP remediation to struggling readers is very relevant and must take into consideration. Both parents and struggling readers were oriented on the program, curriculum, and processes of the remediation. As mentioned in the study, technology although it caters to new ways in presenting information, it is then useless if not properly utilized, unless used and accepted for good, only then improve learning, (Ansari, et al., 2017)They were also trained on computer operation relative to the activity, which includes the creation of email account manipulation of software; clicking the link forwarded in messenger or Google Mail directed to the online module, playing the video, and answering questions to check comprehension.

\section{Participants of the Study}

This study is focused on the selected 35 struggling readers out of 70 enrolled grade 6 pupils of Demesa Elementary School in the school year 2018-2019. They were selected through purposive sampling, based on the result of their pre-assessment reading inventory in English. Using the standard manual in assessing reading level, Philippine Informal Reading Inventory (Phil-IRI Manual, 2018) the assessment was conducted as part of DepEd-ECARP (Every Child A Reader Program) which aims to identify the reading level of all pupils enrolled in the same level and determine pupils needing much reading attention to remediate them.

This research did not give much emphasis on word recognition since the result shows that all 70 grade 6 pupils are in the instructional and independent level and their reading speed is in the average and fast category. Despite their achievement in word recognition, they failed to understand what they have read. Their comprehension score in English shows their level of understanding of the printed text. Contrary to the word recognition and reading speed result 
there are still 35 grade 6 pupils categorized as frustration readers or classified in this action research struggling readers.

Table 1: Percentage Score of Grade Six Frustrated Readers in Phil - IRI

Pre - Assessment

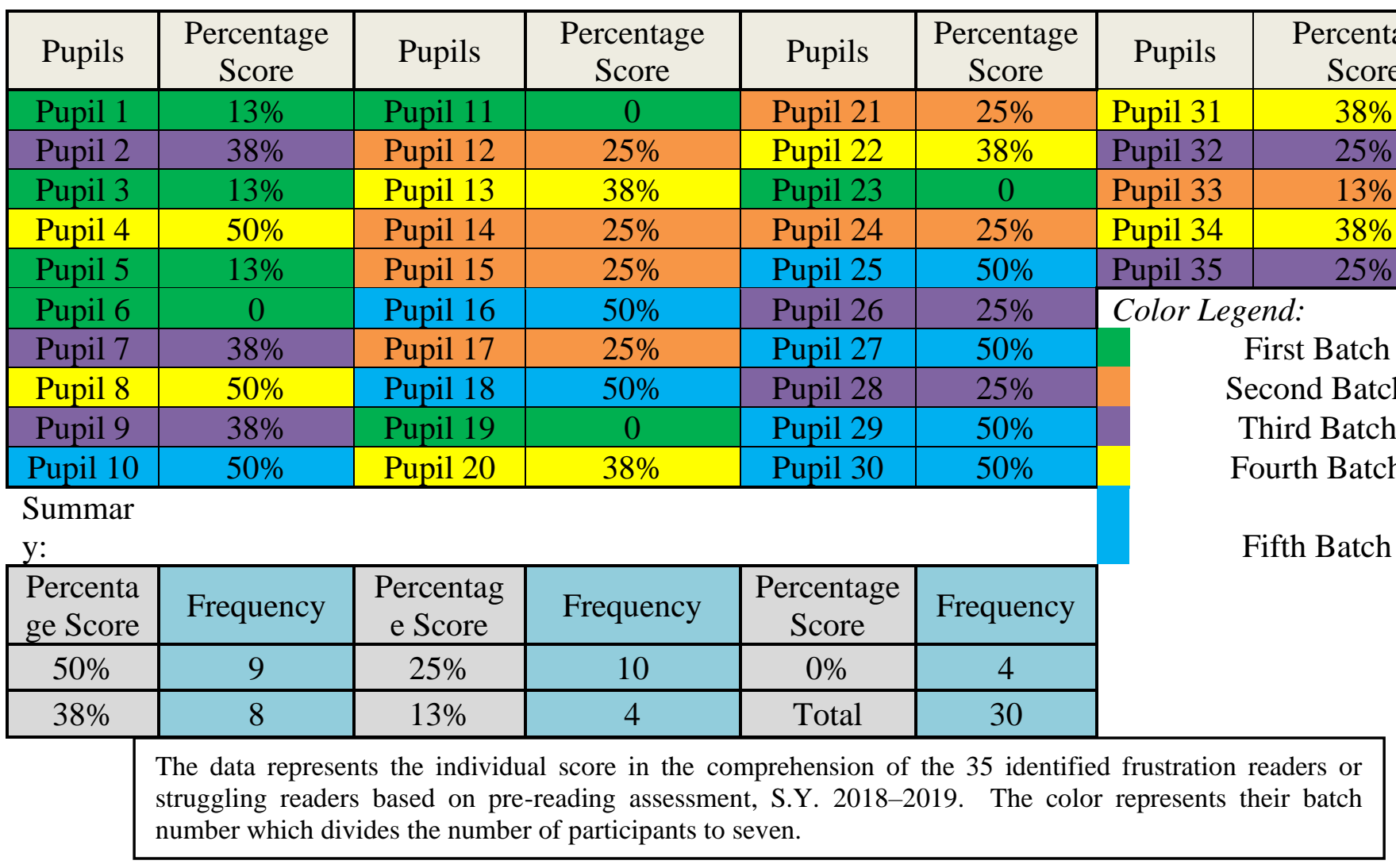

Table 1 shows the pre-assessment comprehension result of the 35 grade 6 pupils classified as struggling readers. This is a proof that out of 70 grade 6 pupils there are 35 who need to undergo COLLAP for comprehension remediation. Evident from the scores they gain after the assessment using the interpretation of Pikulski, (1987) they did not satisfy the required score of Phil-IRI. Interpretation suggests that reading comprehension percentages ranging from 0 to $57 \%$ are classified frustration readers, this is the score from 0 to 4 (Phil-IRI Manual, 2018) to be categorized as instructional to independent the score should be from 5 to 8.

From the distribution of correct responses, the result shows that $80 \%$ or 29 of the struggling readers can comprehend the literal and or interpretation level, while the remaining $20 \%$ or 6 , somehow correctly responds to critical and applied. This implies that struggling readers are already familiar with the literal and interpretation approach, however, they need to be equipped in critical and applied.

\section{Research Environment}

Because of the limited number of computers, the 35 struggling readers were divided into five batches, each batch with seven participants (see Table1). Two batches were scheduled in the first 30 days and another two batches for the second 30 days and then the last. The use of android and smartphones and or other gadgets happen during the absence of the struggling reader or distance learning which occurred in very minimal time; this is to prevent loss of momentum and miss the chance of engagement. 
Time of every engagement varies from pupils to pupils; because reading speed is not used to measure their reading comprehension. It is just to emphasize that readers' allotted hours will be determined by their time of accomplishment in every story a day.

It is important to consider the attention span of pupils and their learning conditions at a particular moment. The researchers use the e-classroom of the school as the venue of the intervention and secure the place with any possible destruction so the struggling readers will be able to focus on the remediation.

\section{Figure1. The e-classroom set-up for the struggling readers}

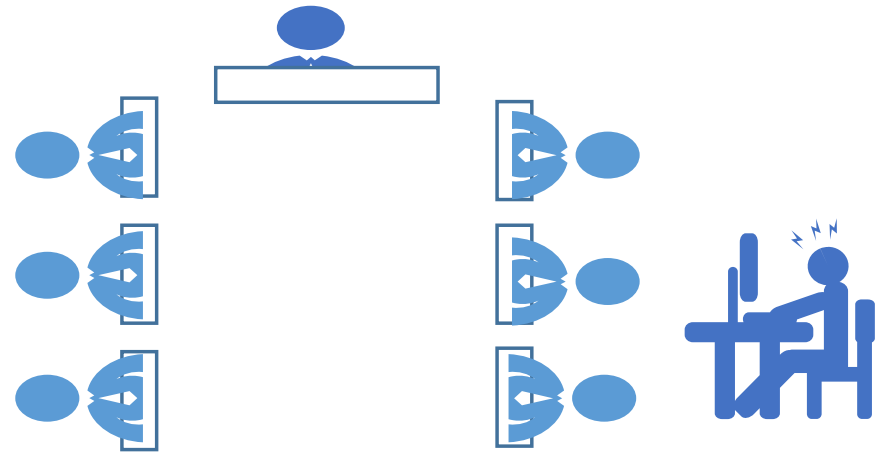

This is the actual set-up of the e-classroom used in COLLAP. There are six side desktops controlled by the central server located in the in the middle, but because of insufficient number of the computer, the central server is also used by the assigned struggling readers while the teacher sits on the side for pupils' inquiry and support.

Illustration in figure 1 shows the actual setup of the COLLAP environment. Seven functional computers are used by every batch. Each participant has a designated computer so the researcher can monitor the attendance for the face-to-face online module. This is also the place where the orientation of the 35 struggling readers together with their parents took place.

The researcher during home visitation identified a conducive area for instances of distance or remote learning, in case the struggling reader is absent in the scheduled face-to-face engagement. Parents are trained in handling psychologically their children, they are also oriented on the curriculum and program of COLLAP and trained on the manipulation of technological platforms available in the house.

\section{Research Materials}

Preliminary to conduct of this action research, the researchers familiarize themselves with the 35 struggling readers. Using the Home Visitation Survey Form (HVSF) of DepEd the researchers personally visited the struggling readers in their house. Anecdotal records are also collected as a basis for their academic performance and decorum. Medical records were also consulted for verification of physical health conditions that might be a factor of reading disability. Through the use of gathered preliminary data, the finding reveals that struggling readers are academically left behind learners, and because of this they refuse to participate, and some of them even become nuisance in class, however, because of parents' consent and with available platforms at home and school, they will willingly participate and undergo COLLAP. 
COLLAP online module has two phases, the viewing phase and the comprehension phase. The viewing phase is a combination of 20 downloaded stories from YouTube and original stories created using available software. Stories were selected based on its background, culture, values, and appeal that are Filipino, to touch the schema of the struggling readers, which all play an important role to simplify understanding the story, (Al Asmar, et at., 2018). These stories are animated with captions, audio, and video presentation, which enhances pupils' comprehension and triggers their attention to focus directly on purpose (Sun, et al., 2019). To attain a positive result, it is vital not to bombard them and rush their activity. Only one story was used each day.

After each story, struggling readers have to proceed by answering the comprehension phase, which adopts the four-comprehension approach: Literal, Interpretive, Critical, and -Applied, (Phil-IRI, 2018).

\section{Data Collection and Analysis}

Although questions were categorized into four, the result of each story was not treated in a category, instead to a percentage score as a whole. These categories are necessary for identifying which comprehension level the struggling readers find difficulties to immediately remediate them.

To gauge comprehension results, the researcher adopts Phil-IRI's treatment of score and design of measurement (Phil-IRI Manual, 2018).

$$
\begin{aligned}
& \text { Comprehension (C): No. of correct answersx } 100=\% \text { of CR } \\
& \text { No. of questions }
\end{aligned}
$$

Using the formula given, the score of each struggling reader has a corresponding equivalent, in which results from every story were graphed to identify changes. After the post-test, results of the reading ability of the 35 struggling readers were interpreted and categorized using the Comprehension Reading Profile by Pikulski, (Phil-IRI Manual, 2018) to check for improvement.

Table 2: Reading Comprehension Profile by Pikulski

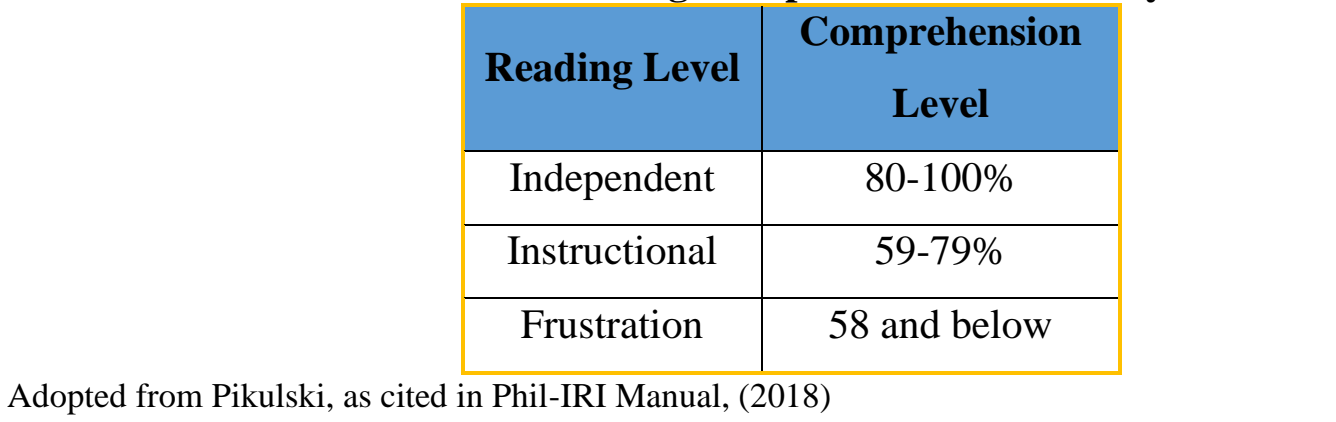

The results of the pre and post-test were compared to be able to identify the increase or decrease in reading comprehension level. T-Test Two-Sample Assuming Equal Variance was used as a statistical treatment to evaluate the data being compared.

\section{Ethical Consideration}

The researcher took all considerations of the gender sensitivity issues, personal beliefs, previews, and perceptions of the participants. Responses were treated with confidentiality and kept personal biases at bay. The manner of the focus was deeply observed and noted. Each of Copyright (C) GLOBAL ACADEMIC EXCELLENCE (M) SDN BHD - All rights reserved 
the responses of participants was noted accordingly. The responses were interpreted and supported by related studies.

Finally, the researchers perform the COLLAP remediation procedure by meeting the participants. This was done daily with agreement among parents that all data collected will be known only by them.

\section{Research Results and Discussion}

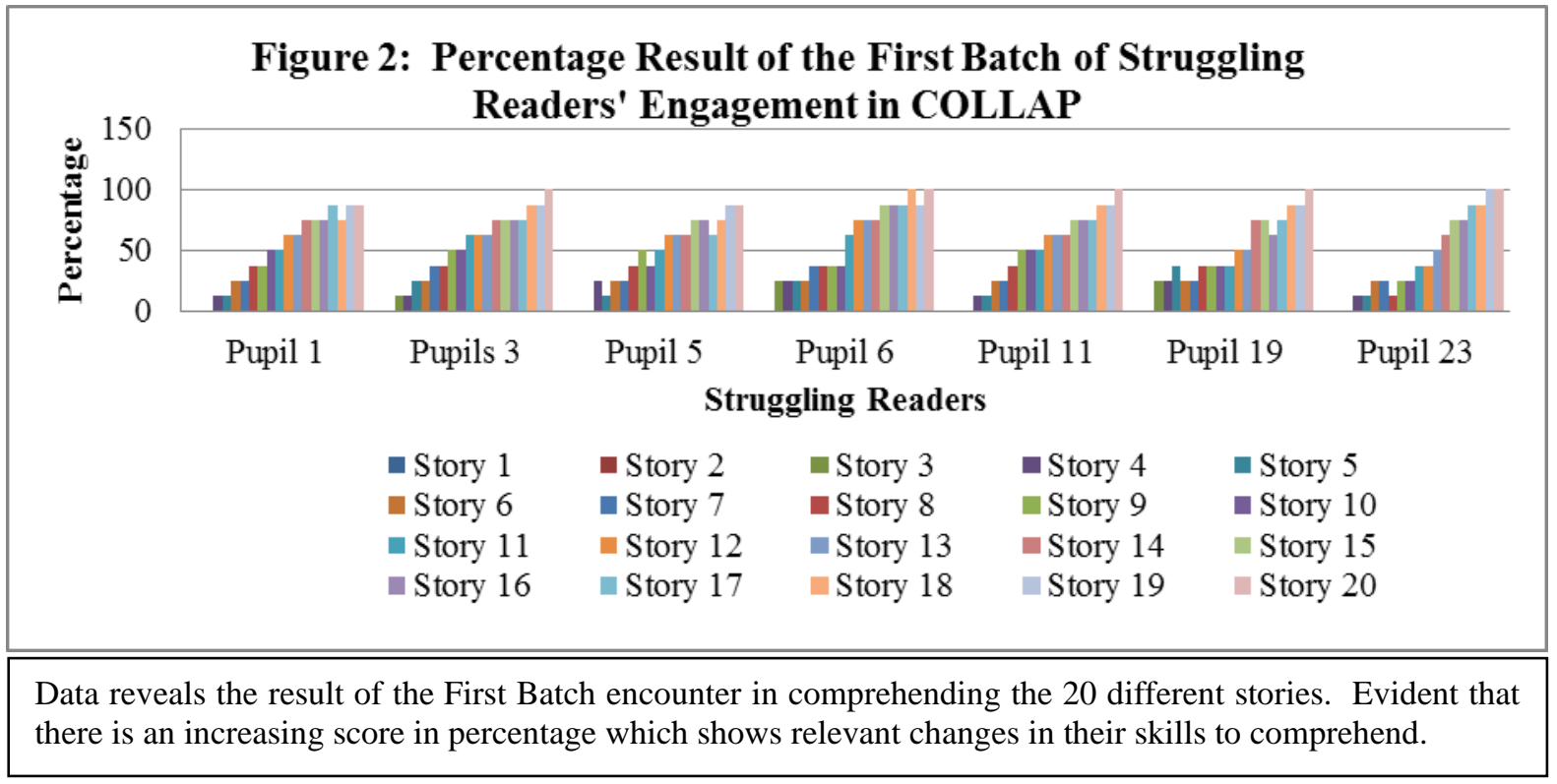

Figure 2 reveals that from story 1 to 8 struggling readers are still at the frustration level, notwithstanding the percentage score represented by the bar shows that their comprehension performance is gradually improving. As the struggling readers continue their engagement the graph shows that three among the struggling readers are beginning to gain an instructional level in story 9. The development of struggling readers from frustration to instructional is visible from story 9 to 16 . And as they pursue the engagement in stories 17 to 20 the data shows a shift from instructional to independent.

Even though absences and distance engagement on the same schedule were committed by pupil 1 in the $6^{\text {th }}$ story all 7 participants attain the same percentage score of 25 . Pupil 19 also failed to attend face-to-face engagement in story 17 and 19, and he interacted through distance engagement; the score in story 17 is $75 \%$ and in story 19 is $87.5 \%$, much higher in the previous comprehension.

The result reveals that teaching the strategy is effective in increasing the comprehension ability of struggling readers. Regardless of face-to-face or distance learning the teacher's support in school and the parent's motivation at home gives a positive result. This also shows that awareness of parents in the curriculum and program enables them to respond to pupil's inquiries positively. 


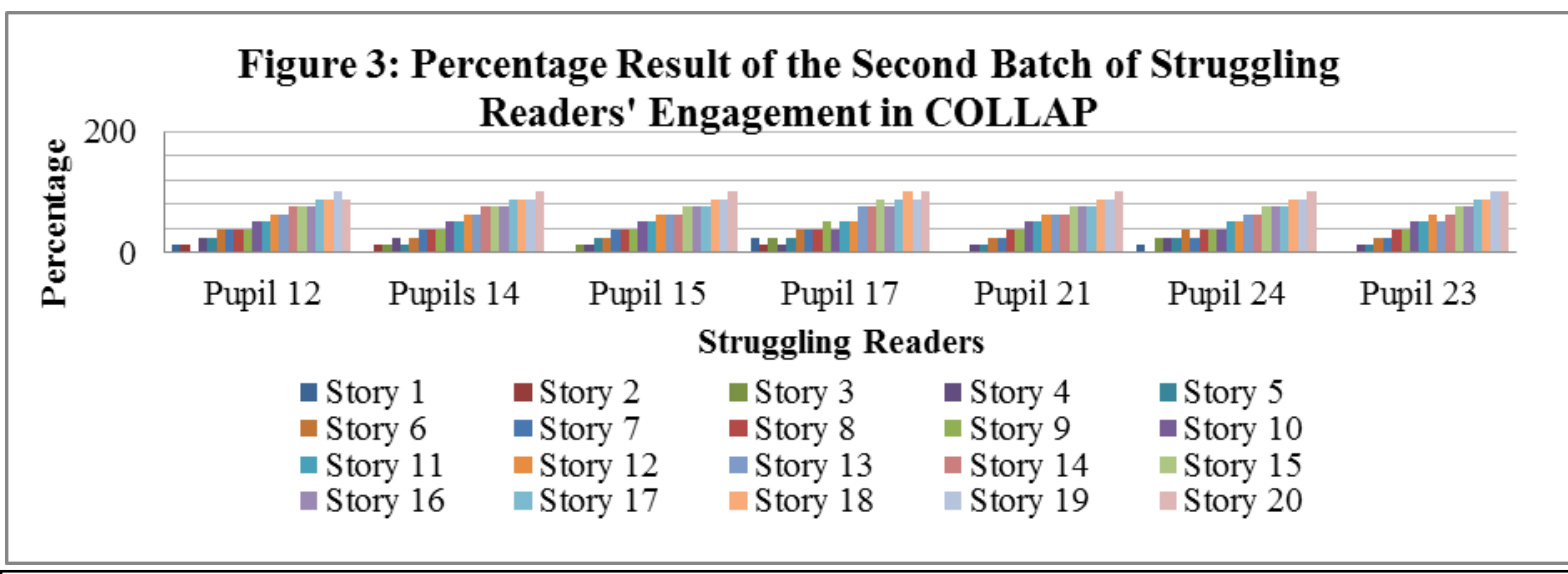

This is the result of the Second Batch engagement from the first to the twentieth story. Evident in the graph the changes in reading comprehension result of the struggling readers.

Figure 3 is the batch of pupils with a $13 \%$ to $25 \%$ score during the Phil-IRI pre-assessment. The data shows that their comprehension score for story 1 is higher than the first batch. Out of seven pupils, three of them did not start with a zero-score compared to the first batch. This shows that they already have stock knowledge in meaning and comprehension but not yet in mastery level.

During the pre-assessment their correct responses come mostly from literal and interpretive, this shows that they are more advanced than the previous batch. This batch exhibits a little slow development from frustration to instructional as seen in the data; it takes 11 stories for them to step to another level and it takes 5 stories for them to develop to independent. The researcher finds this batch full of destruction because of the schedule, which is before lunchtime, and pupils' mindset is games and playtime. However, the intervention made by the researchers led them to focus.

The distance learning of four pupils that happened in the last three stories does not indicate any effect in their comprehension level. Evident that the four levels of comprehension are already familiar to them, and they can perform and respond correctly through their background knowledge.

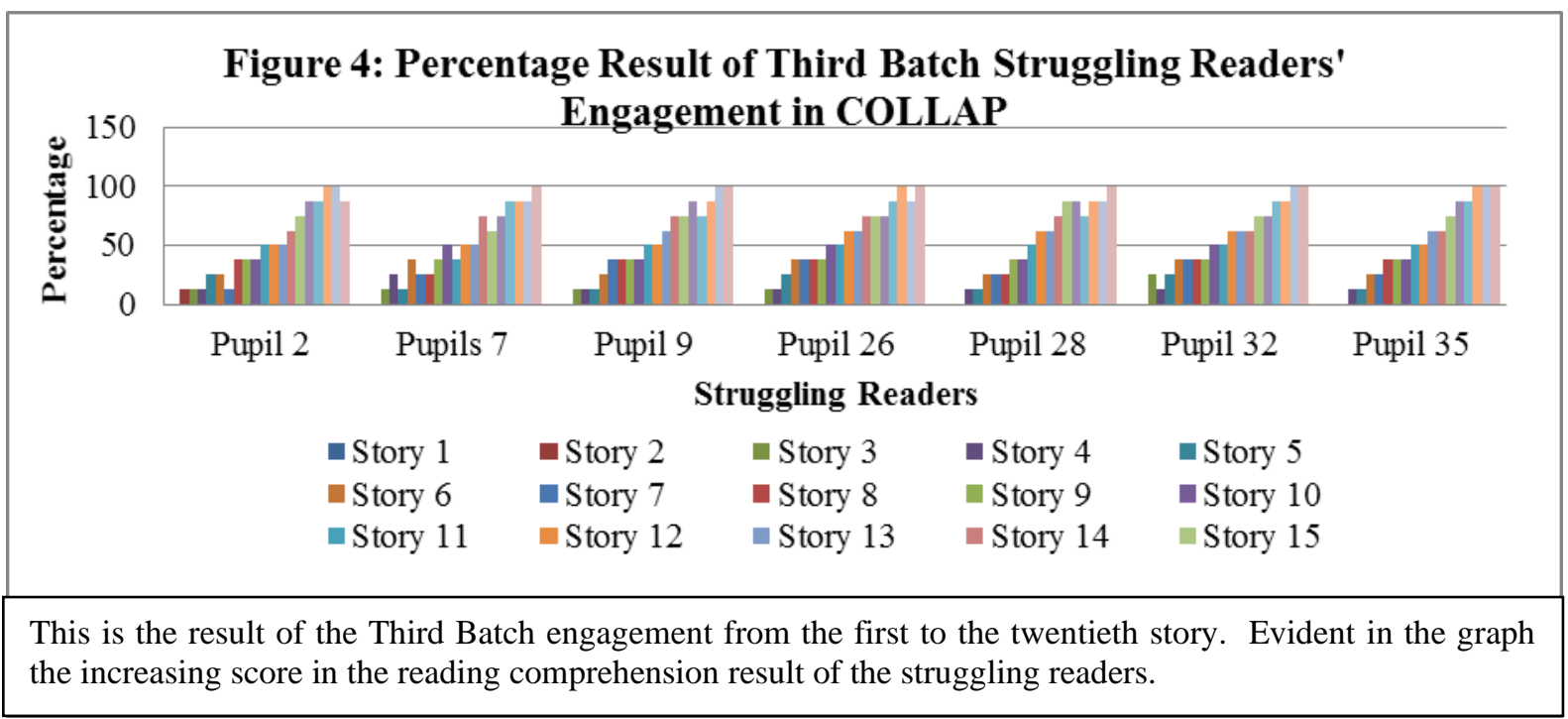


Figure 4 represents the performance of the third batch of struggling readers which engagement is every after class in the afternoon. Contrary to their comprehension preassessment result, the scores of their first and second story are unexpectedly zero. Similar to what the researchers did on the previous batches, the researchers identify the problems through struggling readers themselves with their parents. As a result, the batch has undergone refresher training to capacitate them in the process.

As an outcome of refresher training, evident in their comprehension scores that it takes 10 stories for them to step to the next level instructional. The distribution of correct responses tells that they are already able to answer some questions in a critical and applied level but still need more reinforcements to develop.

It takes four stories in instructional level, stories 12 to 16 , to improve to independent level and the remaining stories 17 to 20 enable them to master the strategies of the four levels of comprehension.

Constant communications to the parents of this batch show positive feedback among struggling readers. Parents' and Teachers' support has a great impact on them. Evident in their performance, it reveals that both parents' and teachers' coordination is important. It is good that in this batch no learners committed absence and parents do frequent follow-up at homes.



This graph represents the comprehension performance of the fourth batch of struggling readers, who underwent COLLAP for 30 days. Evident in the graph is the increase in the seven pupils' comprehension, indicating that COLLAP has a positive effect on their reading performance. Their pre-assessment score shown in table 1 ranges from $38 \%$ to $50 \%$ with a distribution score mostly between literal and interpretive.

In the first story, none of the pupils get any correct responses. In story 2 only pupil 4 got $12.5 \%$ while the rest remain no correct responses. The researchers in this scenario make consultations and intervention among the seven pupils with their parents, to identify the problem and create necessary solutions. 
After retraining seven struggling readers of batch four, they started to gain correct responses in the succeeding stories. As shown in the comprehension scores, this fourth batch is gradually getting high as they finally end in the twentieth story.

In this batch pupil 4 engaged in distance learning, in stories 8, 9, and 11, however, the comprehension score he obtains is similar to those in face-to-face engagement. Pupil 13 also committed absence in stories 14 and 20 however, the correct responses are at the same level as the others. Pupil 31 failed to attend in face-to-face engagement in stories 18, 19, and 20 but evident in the score attained, it does not affect comprehension performance.

Describing the performance of the fourth batch as shown in the graph their gradual improvement from being in frustration level to instructional then independent was attained in face-to-face and distance learning, showing that the most important factor that affects their learning is the guide and support they gain from parents and teachers.

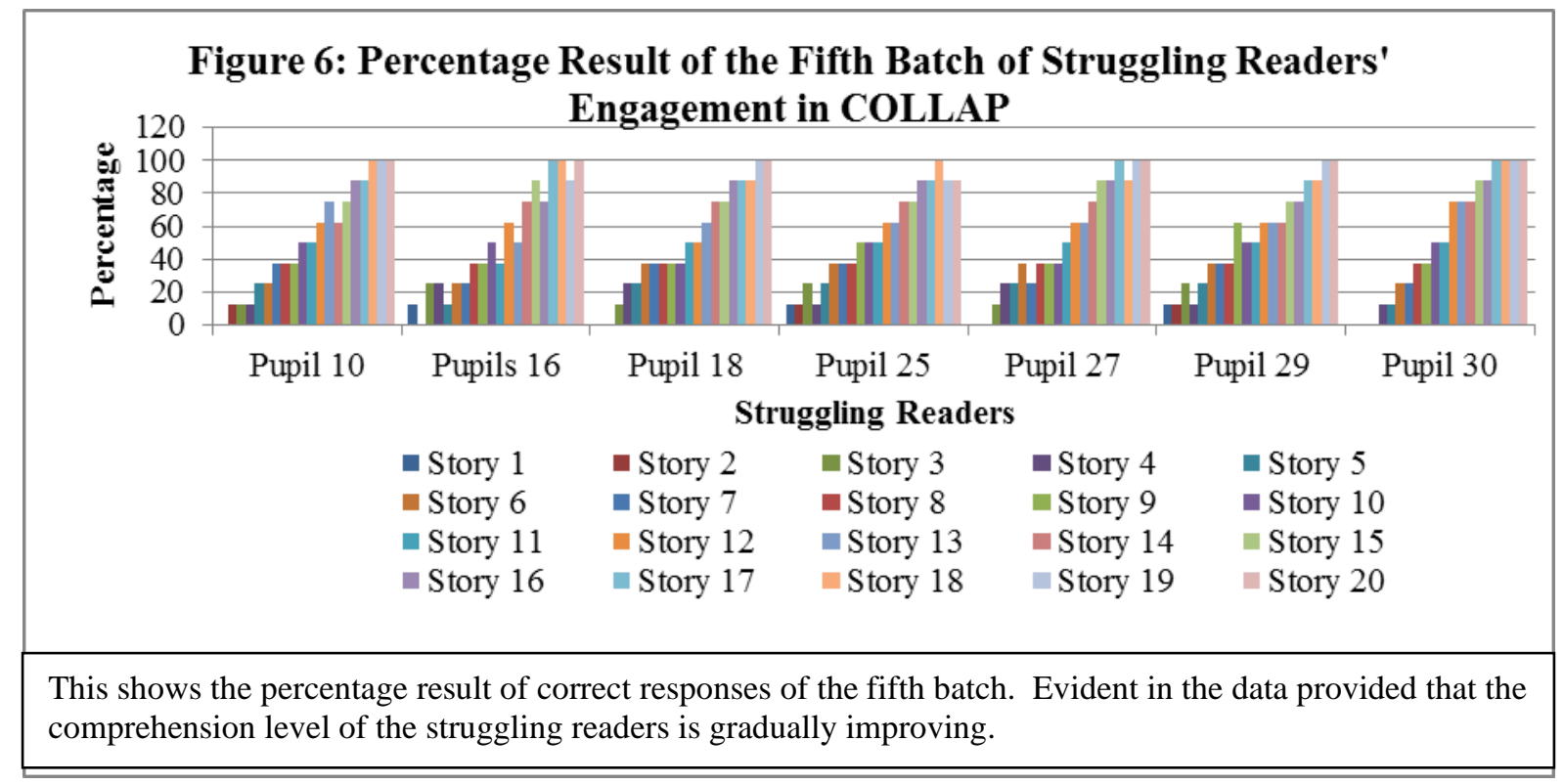

This is the graphical representation of batch five of COLLAP. In this batch only pupil 30 underwent especial support in computer operation, the score gains from the first to the third story does not indicate failure to comprehend, and instead, it indicates more of failure to operate computers as well affected by lack of confidence of the child to express oneself. This problem was dealt with by the researchers with a supportive environment and caters to the pupil's needs.

The pre-assessment score of this batch is higher than the previous batches, thus the comprehension score shows faster improvement than the others. Most of them remain in frustration level up to story 11, but the distribution of scores shows that some of them are already able to answer the critical and applied level, and this is a good indicator that batch five already are equipped with the ability that needs to be furnished for mastery.

Comparing the comprehension scores of those pupils in distance learning, pupil 10-story 9, pupil 16-stories $9 \& 13$, pupil 27 in stories 18, $19 \& 20$, and pupil 29 in stories 19 and 20, to those in face-to-face, the result does not show any decrease, ideally, this reveals that whether face-to-face or distance engagement, there is no effect at all. 


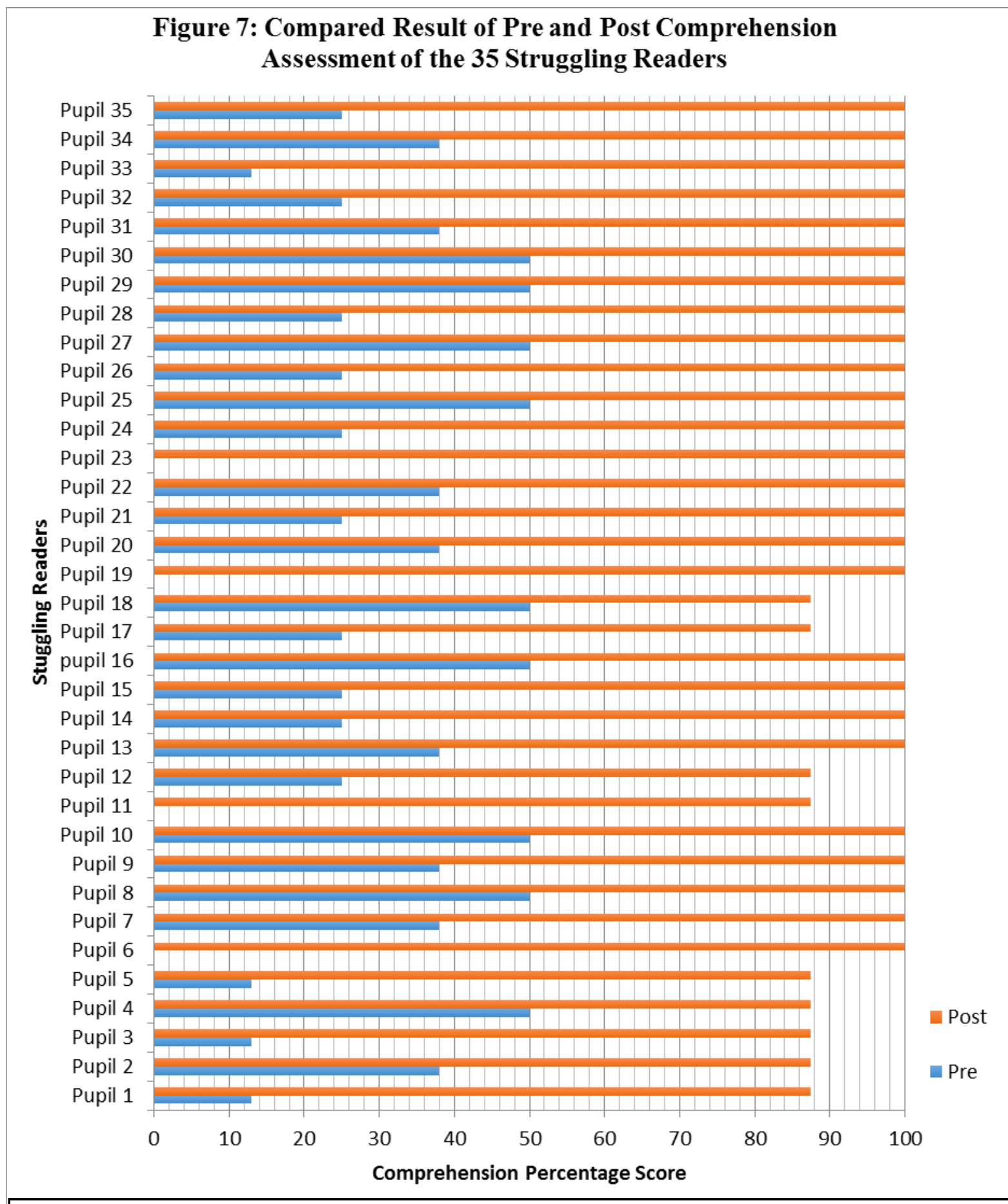

The graph shows the pre and post-reading comprehension assessment results of the 35 struggling readers who undergone COLLAP in 30 days.

Using the pre-assessment result as the basis of the study, the result of each pupil during remediation, and the post-assessment result, the comparison shows the difference in comprehension score of the 35 struggling readers from pre to post-assessment. The improvement in reading comprehension can be seen in the distance among bars. From Figure 2 to Figure 6, the result of COLLAP implementation to the 35 struggling readers shows that all struggling readers have encountered difficulty in the first to second and some on the third stories. Findings show that these incidents indicate issues to be solved to prevent further problems which the researchers immediately resolved. Evident in the succeeding stories that 
all struggling readers begin to gain correct responses showing progress visible in the graphs provided, and as they continuously engage in the stories, it reveals that struggling readers are gaining increasing scores. Even though there are some downs, still COLLAP shows progress in their reading comprehension skills.

Although the pre and post-assessment were conducted using the printed text the data indicate that technology-assisted reading can remediate the problem in comprehension among grade 6 pupils. This also shows that comprehension strategy must be developed through appropriate ways, so that once the strategy is already mastered the pupils can comprehend whether in technology-assisted or printed text.

Evident that whichever modality; face-to-face or distance learning does not result in any learning differences, instead it is the parents' participation which has a greater impact on their performance. This reveals that elements affecting pupils' development must always be considered to attain improvement such are; parental support, pupils differences, and schema, or background knowledge. Use pupils' interest to make them participate and through this, their attention can be caught, because focus is very important and from then, they will learn as they participate. The tougher the story, the more support must be given, so that they feel comforted which leads to their perseverance.

Conspicuous in the result of the pre and post assessment, the graph indicates that the target $100 \%$ instructional or independent readers were attained. Comparing the result of pre and post assessment, all struggling readers achieved the highest interpretation independent. This reveals that technology-oriented instruction leads to positive learning outcomes.

Table 2: Result of the t-Test Two-Sample Assuming Equal Variances of the Struggling Readers

t-Test: Two-Sample Assuming Equal Variances

\begin{tabular}{|l|r|r|}
\hline Mean & 30.17143 & 96.78571429 \\
\hline Variance & 268.1462 & 30.72478992 \\
\hline Observations & 35 & 35 \\
\hline Pooled Variance & 0 & \\
\hline Hypothesized Mean Difference & -22.796 & \\
\hline df & $7.31 \mathrm{E}-34$ & \\
\hline t Stat & 1.667572 & \\
\hline P(T<=t) one-tail & $1.46 \mathrm{E}-33$ & \\
\hline t Critical one-tail & 1.995469 & \\
\hline P(T<=t) two-tail & & \\
\hline t Critical two-tail & & \\
\hline
\end{tabular}

Using the t-Test Two-Sample Assuming Equal Variance determines if the average score of the second test has improved over the average score of the first test. The Mean result of the pre-assessment (30.17) compared to post-assessment (96.79) shows a difference of $66 \%$ 
telling that performance of the 35 struggling readers in Reading Comprehension increases. Table 2 also shows that the degree of freedom (DF) or the amount of information provided in this study is 68. The t Stat result (-22.5) also shows less than the one - tail result (7.31) telling that the implementation of COLLAP created a positive result to 35 struggling readers.

\section{Conclusion}

COLLAP assists struggling readers to improve reading comprehension ability. As previously mentioned, effectiveness of the reading program depends on its appropriateness and suitability to the population. It is important to know your pupils and what they need, how they learn, and what they already know to effectively improve them.

Video-assisted instruction facilitates processing meaning in literature. Similar to the conclusion by Mohammadian, (2018) that video-assisted instruction is an effective material in teaching reading especially in non-native speakers of English. Struggling Readers as they read and watch the animated videos with captions easily comprehend, noticeable on the consecutive improvement in their performance during implementation. Contrary to the printed text, animated videos touch the audio-visual learners' macro skills; listening, reading, and viewing, which further their understanding of the story.

Digital technology (computers, gadgets, etc.) creates a positive motivation among learners, especially that millennial and generation $\mathrm{z}$ is described digitally inclined. They enjoy much of their activity especially if it is with the use of technology. Their curiosity drives them to participate enthusiastically in watching videos and answering questions on the online modules and find how they improved or what their score is. Cited on the result of the study of (Francis, 2017) that students feel motivated in the use of technology as long as the educators themselves are fond of using it effectively.

Repetition of patterns and processes develop mastery, it can enhance memory performance, (Zhan, et al., 2018). Struggling readers during their engagement in the different stories exhibit an increase in their score as they continually do the procedure and encounter the questions. Struggling readers are able to master how they should answer literal, interpretive, critical, and applied questions. This shows that they have developed an understanding of the technique of answering different types of questions. To attain positive comprehension, the learners should also learn the techniques on how they will comprehend the story. And as they master the technique, they will continuously improve comprehension as they pursue in the succeeding grade level.

According to Good, (2019), parental involvement increases pupils' performance. In this action research, whether face-to-face and distance learning the participation of parents became of utmost importance. This recognizes the role of parents in the pupils' development as evident in participants' performance. Computer technology offers a range of information both useful and harmful, and it is important that parents properly guide their learners. It is shown in this study that parents should also have experience in the process and information of the program, and curriculum the learners will undergo, to help them guide their learners in doing the activity and help them perform well. It is their role as well to give words of encouragement among their child, because support is important to struggling readers rather than disappointment. As the parents are getting more involved, the more the struggling readers are attaining high achievement in performance, (Cole, 2017). As parental involvement continues, so as the pupils' academic performance nurtured and enhanced. 


\section{References}

Abba, Habib Mohammed, Mustapha, Muhammad Ali, \& Ali, Hajjakaltum. (March 14, 2019). Use of Computer Assisted Instruction to Improve Students' Reading Skills in the English Language. i-manager's Journal on English Language Teaching.

Abragan, Fernan F. \& Hambre, Milagros M. (2017, March). Video-Assisted Instruction and Performance in Science and Health of Grade 6 Pupils at Naawa Central School. Journal of Education \& Social Policy, 7(1).

Ahmadi, M. R. (2018, June 20). The use of Technology in English Language Learning: A Literature Review. International Journal of Research in English Education, 3(2).

Al Asmar, Abdul Rahman, \& Javid, Choudhary Zahid. (2018, March 17). Role of Content Schema in Reading Comprehension among Saudi EFL Students: EFL Teachers' Perspective and Use of Appropriate Classroom Strategies. International Journal of Applied Linguistics and English Literature, 8(4).

Altin Mehmet and Saracaloglu, Asuman Seda. (2018). Effect of Reading Comprehension Instruction Enriched with Cultural Materials on English Learning. Education Resources Information Center, 5(1), 14.

Amin, M. R. (2019). Developing Reading Skills through Effective Reading Approaches. International Journal of sciences \& Humanities, 4(3), 35-40.

Ansari, Ali Akbar, Farrolchi, Farahman \& Mahboudi, Hamid Reza. (2017, July). Incorporating Computers into Classroom: Effects on Learners' Reading Comprehension in EFL Context. International Journal of Applied Linguistics and English Literature.

Bonnamy, R. (n.d.). English Comprehension. Retrieved from Weebly: https://www.englishcomprehension:weebly.com

Cole, S. A. (2017). The Impact of Parental Involvement on Academic Performance. Education Resources Information Center. Retrieved from https://eric.ed.gov/?id=ED577825

Department of Education. (2019, December 06). Retrieved from A NSW Government website: https://education.nsw.gov.au

(2010). Department of Education Computerization Program and integration of ICT. Manila, Philippines: Department of Education.

Edillan, R. G. (2018). Good Quality Education Now for a Better 2030 and Towards Ambisyon 2040 Education Summit. Philippines: National Economic and Development Authority.

Eliminating Illiteracy, Modernizing Education \& Strengthening Tolerance. (n.d.). Retrieved from Ministry of Education: www.education.gov.gy

Essential Reading Comprehension Skills. (2015, December 16). Retrieved from Study.com: https://study.com/academy/lesson/essential-reading-comprehension-skills.html

Estremera Michael L. \& Estremera Geraldine L. (2018, July). Factors Affecting the Reading Comprehension of Grade Six Pupils in the City Division of Sorsogon, Philippines as Basis for the Development of Instructional Material. Asia Pacific Journal of Education, Arts, and Sciences, 5(3).

Francis, J. (2017, May). effects of Technology on Students Motivation and engagement in Classroom-Based Learning. All Theses and Dissertations, University of New English. Retrieved from https://dune.une.edu/cgi/viewcontent.cgi?article=1120\&context=theses

Gans, K. C. (2019, September 24). Theories. Retrieved from Verywellmind: https://www.verywellmind.com 
Good, A. H. (2019). The Effect of Parental Involvement on Reading Sucess of Kindergarten Students. Master's thesis, Goucher College United States. Retrieved from https://www.phdfood2019.it/wp.context/uploads/2019/05/APA-Guide_2017.pdf.

Huggins, D. (2009, November 19). Pearson Learning Solution. Retrieved from Pearson It Certification: https://www.pearsonitcertificate.com

Hung, D. (2001, December). Theories of Leaning and Computer-Mediated Instructional Technologies. International Council for Education Media, 38(4), 281-87.

k12 Learning Liftoff. (2017). Retrieved from K12 Learning Liftoff: https://www.learningliftoff.com/how-parental-involvement-benefits-the-entireeducational-process/

Keyser, A. (n.d.). Why is Reading Important. Retrieved from Worksheet Cloud: https://www.worksheetcloud.com

Kucukoglu, H. (2012). Improving Reading Skills Through effective Reading Strategies. Akdeniz Language Studies Conference 2012, 710.

Leahy, Marie A., and Fitzpatrick, Nicole M. (2017). Early Reader and Academic Success. Journal of Educational and Developmental Psychology, 7.

Longsdon, A. (2019). Reading Comprehension Problems. Retrieved from Very Well Family: https://www.verywellfamily.com/learning-disability-in-reading-comprehension2162449

Maloes M.L. Muijselaar, Nicole M. Swart, Esther G. Steenbeek, Mienke Droop, Ludo Verhoeven \& Peter F. deJong. (2017). Developmental Relations Between Reading Comprehension and Reading Strategies. Journal Scientific Studies of Reading, 21(3).

McEwan, E. K. (2020). All About Adolescent Literacy Resources for Parents and Educators of Kids in grades 4-12. (WETA Washington D.C.) Retrieved from Teach the Seven Strategies of Highly Effective Readers: www.adLit.org

Mohammadian, A., Saed Amin, N., \& Shahi, Y. (2018). The Effect of Using Video Technology on Improving Reading Comprehension of Iranian Intermediate EFL Learners. Advances in Language and Literacy, 9(2). Retrieved from https://files.enc.ed.gov/fulltext/E51178257pdf.

(n.d.). Retrieved from UNESCO Institute for Statistics: http://www.unesco.org/new/en/natural-sciences/science-technology/overview-ofunescos-work/unesco-institute-for-statistics/

Philstar. (2019, September 27). National Literacy Month. UN Ranks Filipinos as most Literate in Southeast Asia.

Ponce, Hector R., Richard E. \& Lopez, Mario J. (2013). A Computer-Based Spatial Learning Strategy Approach that Improves Reading Comprehension and Writing. Educational Technology Research and Development, 61(5).

Robinson, J. M. (2018). Evaluation of Teaching Methods to Improve Reading Performance of English Language Learners. Robinson Education Consultation. Retrieved from ERIC.

Rutzler, S. (2017, October 20). Importance of Reading Comprehension. Retrieved from Mathgenie: https://www.mathgenie.com/blog/importance-of-reading-comprehension

Scaraldi, K. (2017, November 29). Education Blog. (text help Ltd. Company) Retrieved 2020, from Texthelp: https://www.texthelp.com/en-gb/company/educationblog/november-2017/five-reasons-struggling-readers-benefit-from-tech

Specht, M. (2015, 03 05). 10 fascinating online Learning. Retrieved from Designing Digitally: https://www.designingdigitally.com

Spencer, B. (2015, January 21). Blog. Retrieved from This Reading Mama: https://thisreadingmama.com/teaching-readers-use-schema 
Sun, H., Loh, J., \& Roberts A.C. (2019). Motion and Sound in Animated Storybooks for Preschoolers' Visual Attention and Mandarin Language Learning: An Eye-Tracking Study with Bilingual Children. American Educational Research Association, 5(2).

Suyitno, I. (2017). Cognitive Strategies Use in Reading Comprehension and Its Contributions to the Students. International Academic Forum Journal of Education, 5(3). Retrieved from https://files.eric.ed.gov.

Tang Kuok Ho \& Intai. (2018). Effectiveness of Audio-visual Aids in Teaching Lower Secondary in a Rural Secondary School. Asia Pacific Journal of Educators and education, 91-106(32).

The Philippine Informal Reading Inventory. (2018). Department of Education.

Tina Ghazizadeh, H. F. (2017). The Effects of Blended Learning on EFL learners' Reading Proficiency. Journal of Language Teaching and Research.

Tobler, J. E. (2015). The impact of computer-aided Instruction on Students Achievement.

USC Libraries. (2020, May 20). Retrieved from Research Guides: https://libguides.usc.edu

Wang, H. (2014). On the Constructivist Teaching of Extensive Reading for English Majors. International Journal of Education and Pedagogical Sciences, 8(3).

Wikipedia. (n.d). Retrieved from top-down and bottom-up Design: https://en.m.wikipedia.org

Writing Commons Department of English. (n.d.). Retrieved from Kent State University: https://www.kent.edu/sites/default/files/files/file/three\%20\%level\%20comprehension $\% 20$ guide $\% 20$ for $\% 20$ active $\% 20$

Yusfarina Mohd Yussof, Abdul Rasid Jamian, SamsilahRoslan, Zaitul Azma Zainom Hamzah, \& Muhammad Kamarul Kabilan. (2012). Enhancing Reading Comprehension through Cognitive and Graphic Strategies: A Constructivist Approach. International Educational Technology Conference, 64, 151-160.

Zhan, L., Guo D., Chen, G. \& Yang J. (2018, July 11). Effects of Repetition Learning on Associative Recognition Over Time: Role of the Hippocampus and Prefrontal Cortex. Frontiers in Human Neuroscience. doi:103389. Retrieved from www.sciencedirect.com 